\title{
Supervisor ratings of productivity loss associated with presenteeism and sick leave due to musculoskeletal disorders and common mental disorders in Sweden
}

Lars Bernfort, Jan Persson, Catharina Linderoth and Kerstin Ekberg

The self-archived postprint version of this journal article is available at Linköping University Institutional Repository (DiVA):

http://urn.kb.se/resolve?urn=urn:nbn:se:liu:diva-176008

N.B.: When citing this work, cite the original publication.

Bernfort, L., Persson, J., Linderoth, C., Ekberg, K., (2021), Supervisor ratings of productivity loss associated with presenteeism and sick leave due to musculoskeletal disorders and common mental disorders in Sweden, Work, 68(4), 1091-1100. https://doi.org/10.3233/WOR-213439

Original publication available at:

https://doi.org/10.3233/WOR-213439

Copyright: IOS Press

http://www.iospress.nl/ 
Supervisor ratings of productivity loss associated with presenteeism and sick leave due to musculoskeletal disorders and common mental disorders in Sweden 


\section{Abstract.}

\section{BACKGROUND:}

Health problems due to musculoskeletal disorders (MSD) and common mental disorders (CMD) result in costs due to lost productivity.

\section{OBJECTIVE:}

This study aimed to increase knowledge of employers' productivity loss due to employees' presenteeism and sickness absence.

\section{METHODS}

A web questionnaire was sent to employers of workers who were sick-listed for more than 30 days due to MSD or CMD, response rate: $50 \%, \mathrm{n}=198$. Presenteeism and the impact on productivity before and after sick leave, and the performance of work tasks by replacement workers during sick leave, were measured using supervisors' ratings.

\section{RESULTS:}

The average loss of productivity per sick-leave case amounted to almost 10 weeks, $53 \%$ of productivity loss was attributable to presenteeism and $47 \%$ to lower productivity by replacement workers. Employees with a CMD diagnosis had significantly higher presenteeism-related productivity loss than those with MSD.

\section{CONCLUSIONS:}

Employers experienced substantial productivity loss associated with employees' presenteeism and sick leave. Whether the supervisory rating of presenteeism is preferable to employee self-rating needs to be studied further. The long duration of presenteeism is counter-productive to resource-efficient organisations and indicates the need for improved supervisory skills to identify workers with poor health, both before and after sick leave.

Key words: workplace, costs, work disability 


\section{Introduction}

Health-related absenteeism and presenteeism result in high costs to society due to the cost of health care, rehabilitation measures, and productivity loss. The societal cost of rehabilitation measures seems comparably small compared with the cost of productivity loss [1-4].

Productivity loss has been defined in different ways. One approach is to express it from a societal rather than individual perspective as output loss due to work absence and/or due to presenteeism, i.e. reduced labour input due to illness [5-7]. Productivity loss was defined by Brouwer et al. [8] as "costs associated with production loss and replacement costs due to illness, disability and death of productive persons, both paid and unpaid." Productivity loss due to presenteeism and sickness absence may be caused by both health-related and work-related factors [9]. In a cross-sectional European study based on the European Working Conditions Survey (EWCS) [10], health status was the most important determinant for presenteeism. Work-related determinants were work autonomy, workload, tenure and the work environment. Production loss due to presenteeism is substantial and may involve even larger costs than those of absenteeism [1, 11, 12]. Brouwer et al. [13] found that about $25 \%$ of sick-listed workers experienced productivity losses before absence and $20 \%$ experienced productivity losses after their return to work. Depression has been reported to have the greatest negative impact on productivity and the costs seem in particular to be generated by presenteeism $[3,14]$. A multinational study found that the costs associated with presenteeism due to depression tended to be 5-10 times higher than those associated with absenteeism [3]. Moreover, sickness presenteeism was shown in a prospective cohort study by Bergström et al. [12] to be an independent risk factor for future fair/poor general health, and in another study for future sick leave [15].

Earlier studies have systematically reviewed how the economic evaluation literature estimates productivity changes $[6,7,16,17]$. They found great variations in the methodology used for estimating productivity loss, which makes it difficult to compare study results. Uegaki et al. [17] suggest the use of a more specific stakeholder perspective. Most economic evaluations focus on the costs of absenteeism and interventions, while costs from the employer's perspective are in general missing, and in most cases the methods used to identify and evaluate the costs of such programmes are not comprehensive [18]. From an employer's perspective, productivity loss may occur during a worker's sickness absence, but also due to presenteeism before sickness absence and during re-integration after return to work. During the re- 
integration period, it seems likely that workers will need some time to adapt and regain their normal productivity, especially after long-term sick leave, and employers may have additional costs due to workplace adaptations to promote work ability. Kigozi et al [6] emphasise the need for including costs due to presenteeism in economic evaluations.

There is no consensus or gold standard regarding which measurement method is most appropriate for the assessment of productivity loss due to health conditions and presenteeism [19]. Instruments for measuring productivity loss due to presenteeism have primarily been addressed to employees, who rate their own work performance [20-24]; a recent scoping review identified 24 different instruments [25]. A potential problem associated with self-reports of presenteeism and productivity is the risk of self-report bias [26]. Several factors may influence self-assessments, such as the quality of the relationship with the supervisor, organisational policies for minimising absenteeism, and the degree of support from managers [27-29].

Another possible approach is to allow the supervisors of sick-listed employees to estimate the degree of presenteeism and productivity loss. In a longitudinal study using supervisory ratings of performance and self-rated well-being, Wu et al. [30] found significant positive effects between baseline well-being and performance 2 years later. Well-being change over the study period was positively associated with supervisory ratings of performance, indicating an important association between employee health and organisational productivity. The study also shows that supervisors may be an important source of information on employee performance.

This study's focus is on the employers, for whom employee sick-leave results in costs for rehabilitation (legally required or not), replacements for sick-listed personnel and productivity loss due to presenteeism before and after the sickness absence period. Rehabilitation measures and replacements are concrete costs that should be visible in employers' accounts. In addition to these costs, illness/disease with subsequent sick leave are often associated with loss of work ability and productivity both before and after the actual sick leave period. There is also a risk that replacement workers are not as productive as ordinary (sicklisted) employees. These aspects imply costs for employers that are not directly visible, at least not in the short term, as they do not match any expense or payment. In the long term, however, overall productivity is likely to be affected.

In the present study we investigate the prevalence and magnitude of lost productivity affecting employers in cases of sick leave. We assume that presenteeism and degree of loss of productivity before and after 
periods of sick leave, as well as degree of loss of productivity associated with replacement workers, can be evaluated by employers.

\section{Materials and methods}

Employees who were sick listed due to musculoskeletal disorders (MSD) or common mental disorders (CMD) were randomly selected from the AFA Insurance register. AFA Insurance is owned by Sweden's labour-market parties, covering employees within the private sector, municipalities and county councils. Diagnoses in the register were set by the sick-listing physician according to the ICD-10 system. Sampling was performed with the restriction that half the sample should be sick-listed due to MSD and half due to CMD. Criteria for inclusion of employees were: sick-listed for at least 30 days, aged between 20 and 63 years, and has an employer.

An information letter was sent to the sample requesting permission for the researchers to contact their supervisors/employers. They were also asked to provide their supervisors' contact details.

The study was approved by the Regional Ethics Board, [Edited for Review Process].

\subsection{Measures}

All demographic data were obtained from the AFA Insurance register. All other data were obtained by a webbased questionnaire to the supervisors of sick-listed employees.

\subsubsection{Demographics}

Registry data concerning sex, diagnosis, and number of sick-leave days were obtained from AFA Insurance.

\subsubsection{Predictors}

The questionnaire contained questions on type of employment, educational level and occupation of the employee, the physical, mental and social demands of their work, and the size of the company. The background variables analysed in this paper were diagnosis (CMD or MSD), sex (female, male), age $(\leq 34,35-44,45-54,>54$ years), occupation (white, pink, blue-collar), education (elementary or uppersecondary school, university), and company size (0-49, 50-249, $\geq 250$ employees). 


\subsubsection{Outcomes}

Questions on work performance were based on a modified version of the Work Productivity and Activity Impairment Questionnaire - General Health (WPAI-GH) [21, 31-34]. The questionnaire was adapted to allow responses from our target group supervisors, rather than from the employees. Based on a limited pilot study including 16 pairs of supervisors/employees, face validity of the questions was considered satisfactory. The findings from the pilot study were that the instrument is straightforward to use and easily understood, and concordance was good when comparing responses from supervisors and employees.

In the web-based questionnaire, supervisors of sick-listed employees were asked about their employees' work performance, "Did the health problems affect your worker's ability to perform his/her work tasks before (after) their sick-leave period? For how many weeks? To what degree (ratings on a scale between 0 and 10)?" Productivity loss due to poorer performance by the replacement workers of sick-listed employees was rated by supervisors according to the work performance of the replacement worker compared with the regular employee. Work performance was measured on a scale of $0-10$, where 10 equalled the performance of the regular employee and lower ratings indicated poorer performance.

\subsection{Analysis}

The quantities of lost productivity calculated for each of the periods before, during, and after sick-leave were expressed in lost full-time week equivalents. Data on length of sick leave, which were used to calculate productivity loss associated with replacement workers, were expressed in calendar days (7 days a week) and therefore divided by 7; part-time employment was transferred to full-time equivalents.

During sick leave, a measure of lost productivity associated with replacement workers was obtained by multiplying the number of weeks of sick leave by the difference in productivity due to the hiring of replacement workers, compared with the ordinary productivity of the sick-listed employee. The assumption that replacement workers produce less than ordinary employees is due to the assumption that a learning period is necessary. This might not always be the case which makes the analysis somewhat simplified.

Before and after the period of sick leave, the number of weeks with reduced productivity was multiplied by the average extent of limited productivity (0-10). If, for instance, an employee produces $75 \%$ of what 
she/he normally produces for eight weeks, then the productivity is reduced by $25 \%$ for eight weeks and the productivity loss is equivalent to $0.25 * 8=2$ work weeks.

\section{Statistics}

Descriptive statistics are presented as means, medians, and ranges. Chi2 test was used to test variation in response rates. Differences in mean costs between groups were analysed using Student's t-test or Analysis of Variance (ANOVA). Two-tailed tests with a significance level $p<0.05$ were used throughout. All analyses were performed using IBM Statistics SPSS version 24 (Armonk, NY: IBM Corp).

\section{Results}

\subsection{Demographics}

The web-based questionnaire was sent to 393 supervisors. The response rate was 50\% (198 responses) after two reminders. The sample comprised 98 individuals with musculoskeletal diagnoses (MSD) and 100 individuals with mental diagnoses (CMD); $64 \%$ were female and $36 \%$ were male.

Supervisors responded to the questionnaires for 154 females (78\%) and 44 males $(22 \%)$. The educational level was high school or lower for 104 (61\%), and university education for 66 (39\%). In total, 57 (29\%) were white-collar workers (managers, highly skilled workers, etc.), 93 (47\%) were pink-collar workers (administration, service, care, health care, education), and 47 (24\%) were blue-collar workers (construction, transportation etc.). Almost half of the responding supervisors (45\%) were employed in organisations with more than 250 employees, $22 \%$ came from small and medium-sized enterprises with fewer than 50 employees, and the remaining 33\% were employed in organisations with 51-249 employees. The average duration of sick leave was 261 days $(\mathrm{SD}=119)$.

\subsection{Non-response analysis}

There was no significant difference in the response rate between supervisors with employees who were sick-listed due to MSD (48\%) or CMD (51\%). Occupations with predominantly female staff, such as health care, social care and education were the largest occupational groups in the sample. There was no significant difference in response rate between the occupational categories $(\mathrm{p}=.43)$. (Table 1). 
Table 1: Distribution of occupational categories in the sample, among respondents, and response rate (\%) in occupational categories.

\begin{tabular}{|c|c|c|c|c|c|}
\hline \multirow{2}{*}{$\begin{array}{l}\text { Swedish Standard } \\
\text { Industrial } \\
\text { Classification }\end{array}$} & \multicolumn{2}{|c|}{$\begin{array}{l}\text { Sample } \\
\mathbf{N}=393\end{array}$} & \multicolumn{2}{|c|}{$\begin{array}{l}\text { Respondents } \\
\mathrm{N}=198\end{array}$} & \multirow{2}{*}{$\begin{array}{c}\begin{array}{c}\text { Response } \\
\text { rate }\end{array} \\
\%\end{array}$} \\
\hline & $\mathbf{n}$ & $\%$ & $\mathbf{n}$ & $\%$ & \\
\hline Manufacturing & 35 & 9 & 14 & 7 & 40 \\
\hline Construction & 6 & 2 & 3 & 2 & 50 \\
\hline $\begin{array}{l}\text { Wholesale, repair of } \\
\text { motor vehicles }\end{array}$ & 23 & 6 & 4 & 2 & 17 \\
\hline $\begin{array}{l}\text { Transportation and } \\
\text { storage }\end{array}$ & 21 & 5 & 11 & 6 & 52 \\
\hline $\begin{array}{l}\text { Real estate, } \\
\text { administration, } \\
\text { support service }\end{array}$ & 28 & 7 & 10 & 5 & 36 \\
\hline Education & 54 & 14 & 32 & 16 & 59 \\
\hline $\begin{array}{l}\text { Health and social } \\
\text { work activities }\end{array}$ & 197 & 50 & 110 & 56 & 56 \\
\hline Other & 29 & 7 & 14 & 7 & 48 \\
\hline
\end{tabular}

The response rate from supervisors of sick-listed employees in different age categories did not differ significantly $(\mathrm{p}=.39)($ Table 2$)$.

Table 2: Distribution of age categories in the sample, among respondents, and response rate (\%) in age categories.

\begin{tabular}{|l|l|l|l|l|l|}
\hline Age category & \multicolumn{2}{|c|}{$\begin{array}{c}\text { Sample } \\
\text { N=393 }\end{array}$} & $\begin{array}{c}\text { Respondents } \\
\text { N= 198 }\end{array}$ & $\begin{array}{c}\text { Response } \\
\text { rate }\end{array}$ \\
\hline & $\mathbf{n}$ & $\mathbf{\%}$ & $\mathbf{n}$ & $\mathbf{\%}$ & $\mathbf{\%}$ \\
\hline $\mathbf{2 0 - 3 4}$ & 23 & 6 & 7 & 4 & 30 \\
\hline $\mathbf{3 5 - 4 4}$ & 85 & 22 & 39 & 20 & 46 \\
\hline $\mathbf{4 5 - 5 4}$ & 125 & 32 & 59 & 30 & 47 \\
\hline $\mathbf{5 4} \geq$ & 160 & 41 & 93 & 47 & 58 \\
\hline
\end{tabular}

\subsection{Productivity loss due to presenteeism before and after sick leave}

At the time the questionnaire was completed, $129(66 \%)$ of the 198 workers on sick leave had returned to work either part time (27\%) or full time (38\%). Concerning the period before sick leave, 86 of the 195 
responding supervisors (44\%, 3 missing) stated that employees' productivity was affected. Of these, 72 answered questions on both the duration and extent of the affected productivity. Overall, $46 \%$ of those with CMD and $42 \%$ with MSD exhibited reduced productivity before sick leave. The average duration of reduced productivity among the 72 employees was 21.0 weeks (range 1-52 weeks) and the average productivity rating during this time was 5.0 (range $0-10$ ). When we include the employees whose productivity was not affected, these results translate into an average of 3.5 full-time week equivalents of lost productivity per person for the whole sample. There was no variation in presenteeism before sick leave due to demographic factors.

Concerning the time directly after return to work, the supervisors of 72 employees who had returned to work responded. Of these, 66 gave analysable responses, i.e. stated both the duration and extent of the reduction in productivity, and 44 stated that productivity was affected. The average duration of reduced productivity among the 44 employees was 11.9 weeks (range 2-48 weeks) and the average productivity during this time was 5.4 (range 2-8). When we include the employees with unaffected productivity, an average of 3.1 week-equivalents were lost per person.

\subsection{Productivity loss during sick leave}

A total of 177 of the 198 supervisors answered the question comparing the productivity of replacement employees with that of regular employees. A negative impact on productivity was reported by 108 supervisors while 69 reported no negative impact. Sick-leave periods for the 177 employees were on average 200.5 days (range $30-382)$ and the productivity of replacements $(n=177)$ was on average 7.92 (range 2-10). Sick-leave days for each employee were restricted to the point in time when the supervisor returned the questionnaire, as the questions were related to what had happened up to this point. This means that, for the sick-listed employees who had not yet returned to work at this point, the number of sick-leave days used in this analysis is an underestimate.

The calculation resulted in an average of 6.0 full-time week equivalents of lost productivity per case of sick leave.

The results were tested for differences related to diagnosis, sex, age, occupation, education, and company size (see Table 3). For presenteeism before sick leave, no significant differences between groups were found. For presenteeism after return to work, a significant difference was found only in relation to 
diagnosis, where CMD was associated with higher costs than MSD. Concerning productivity loss during sick leave, significant differences were found for occupation (highly skilled work gave rise to bigger losses) and for education (higher education meant bigger losses).

Table 3. Productivity loss in terms of full-time week equivalents related to diagnosis, sex, age, profession, educational level, and company size.

\begin{tabular}{|c|c|c|c|c|c|c|}
\hline \multirow[t]{2}{*}{ Factor } & \multicolumn{2}{|c|}{ Before sick-leave } & \multicolumn{2}{|c|}{ During sick-leave } & \multicolumn{2}{|c|}{ After return to work } \\
\hline & $\mathrm{N}$ & Weeks & $\mathrm{N}$ & Weeks & $\mathrm{N}$ & Weeks \\
\hline \multicolumn{7}{|l|}{ Diagnosis } \\
\hline Common Mental Disorders & 89 & 2.75 & 84 & 6.63 & 24 & 6.36 \\
\hline Musculoskeletal Disorders & 92 & 4.24 & 93 & 5.04 & 42 & 1.29 \\
\hline Significance between groups & & $\mathrm{p}=0.155$ & & $\mathrm{p}=0.147$ & & $p=0.001$ \\
\hline Total & 181 & 3.51 & 177 & 5.80 & 66 & 3.13 \\
\hline \multicolumn{7}{|l|}{$\operatorname{Sex}$} \\
\hline Female & 142 & 3.59 & 136 & 6.31 & 51 & 3.71 \\
\hline Male & 39 & 3.22 & 41 & 4.08 & 15 & 1.16 \\
\hline Significance between groups & & $\mathrm{p}=0.775$ & & $\mathrm{p}=0.084$ & & $\mathrm{p}=0.156$ \\
\hline Total & 181 & 3.51 & 177 & 5.80 & 66 & 3.13 \\
\hline \multicolumn{7}{|l|}{ Age, years } \\
\hline 0-34 & 6 & 0.97 & 7 & 1.60 & 4 & 2.90 \\
\hline $35-44$ & 36 & 3.12 & 34 & 7.64 & 12 & 2.99 \\
\hline $45-54$ & 54 & 3.32 & 49 & 5.98 & 17 & 4.04 \\
\hline$>54$ & 85 & 3.97 & 87 & 5.31 & 33 & 2.74 \\
\hline Significance between groups & & $\mathrm{p}=0.731$ & & $\mathrm{p}=0.173$ & & $\mathrm{p}=0.918$ \\
\hline Total & 181 & 3.51 & 177 & 5.80 & 66 & 3.13 \\
\hline \multicolumn{7}{|l|}{ Occupation } \\
\hline $\begin{array}{l}\text { Executives, high-skilled } \\
\text { work }\end{array}$ & 55 & 3.17 & 49 & 7.97 & 13 & 4.85 \\
\hline Admin, service, etc. & 83 & 3.45 & 82 & 5.23 & 34 & 3.50 \\
\hline Low skill work, Blue collar & 42 & 4.17 & 45 & 4.61 & 19 & 1.31 \\
\hline Significance between groups & & $\mathrm{p}=0.780$ & & $p=0.046$ & & $\mathrm{p}=0.244$ \\
\hline Total & 180 & 3.53 & 176 & 5.83 & 66 & 3.13 \\
\hline \multicolumn{7}{|l|}{ Education } \\
\hline $\begin{array}{l}\text { Elementary or upper } \\
\text { secondary school }\end{array}$ & 92 & 4.08 & 98 & 5.01 & 43 & 2.19 \\
\hline University & 62 & 3.13 & 43 & 7.81 & 13 & 4.62 \\
\hline Significance between groups & & $\mathrm{p}=0.438$ & & $p=0.015$ & & $\mathrm{p}=0.088$ \\
\hline Total & 154 & 3.70 & 152 & 6.07 & 56 & 2.75 \\
\hline \multicolumn{7}{|l|}{ Company size, employees } \\
\hline $0-49$ & 44 & 3.10 & 44 & 5.94 & 11 & 1.32 \\
\hline $50-249$ & 44 & 2.80 & 41 & 4.94 & 16 & 1.46 \\
\hline$\geq 250$ & 90 & 4.02 & 89 & 6.16 & 38 & 3.43 \\
\hline Significance between groups & & $\mathrm{p}=0.588$ & & $\mathrm{p}=0.671$ & & $\mathrm{p}=0.166$ \\
\hline Total & 178 & 3.52 & 174 & 5.82 & 65 & 2.59 \\
\hline
\end{tabular}




\subsection{Total productivity loss due to presenteeism and sick leave}

The total productivity loss associated with a sick-leave episode is summarised in Table 4. It is worth noting that these costs do not include the costs to companies of hiring replacements. The costs during sick leave are due to replacements performing at a lower level than the regular employees.

Table 4. Average lost productivity before, during and after sick-leave (median, range).

\begin{tabular}{|l|c|c|c|}
\hline & Before sick-leave & During sick-leave & After return to work \\
\hline Productivity affected (n/N) & $181 / 195$ & $177 / 198$ & $66 / 72$ \\
\hline Average duration (weeks) & $8.4(0,0-52)$ & $28.6(29.1,4.3-54.6)$ & $6.9(4,0-48)$ \\
\hline $\begin{array}{l}\text { Average productivity (0-10) } \\
\text { Lost productivity (week } \\
\text { equiv.) }\end{array}$ & $7.8(10,1-10)$ & $7.9(8,2-10)$ & $7.4(7,2-10)$ \\
\hline $\begin{array}{l}\text { Total average lost } \\
\text { productivity (week equiv.) }\end{array}$ & $3.5(0,0-33)$ & $5.8(2.9,0-32.5)$ & $3.1(1.1,0-38.4)$ \\
\hline
\end{tabular}

\section{Discussion}

To our knowledge, this is the first study in which productivity loss related to presenteeism and the sickleave period has been estimated using employers/supervisors as respondents, based on case-specific, realworld data. Therefore, the results are based on supervisors' evaluations of employee productivity, and of the productivity of the replacement during employees' sick leave.

The actual productivity loss associated with cases of sick leave were divided into presenteeism before and after the sick-leave period, in addition to the impact on productivity during sick leave due to the productivity of replacements. We found that productivity loss was quite substantial. Lost productivity amounted to almost 10 full-time week equivalents per case of sick leave. Of the lost productivity, $53 \%$ was attributable to presenteeism before and after sick leave and $47 \%$ to lower productivity by replacements during the sick-leave period.

The subgroup analyses showed significant differences due to diagnosis in productivity loss associated with presenteeism after return to work. As also reported by Evans-Lacko and Knapp [3], common mental disorders, and in particular depression, cause significant reduction of productivity due to presenteeism. Employees who were sick-listed due to CMD needed more time to return to full working capacity than those with MSD, as also shown by the OECD [35]. According to the OECD [35], 74\% of all employees with a mental disorder report reduced productivity at work over the previous 4 weeks, compared with 
only $26 \%$ of employees without a mental disorder, indicating that presenteeism is highly prevalent and has a long duration for employees with mental disorders. Lidwall et al [36] emphasize the need for early detection and prevention of mental disorders in the workplace. In this, employers have an important role in early detection, but also in the process of supporting work ability and productivity for employees with health problems [37-39].

Productivity loss during sick leave was significantly higher for highly skilled occupations and for those requiring a high level of education. The most highly skilled workers had on average a total production loss of 16 weeks compared to about 10 weeks for the least skilled workers. The most educated workers were associated with almost 16 weeks of lost production compared to about 11 weeks for the least educated. In our study, supervisors stated in the questionnaire that highly skilled employees are more difficult to replace, and that the quality of the performance of replacements is lower in jobs that require both high education and skill. From a cross-sectional study, Merrill et al. [40] report that managers and professionals had the highest level of presenteeism, which was related to having too much to do and too little time to do it. Managers are more likely to attend work if they are unwell [29], but may also have greater flexibility by performing some work from home or by adjusting working hours.

We found no previous study that analysed how managers rated productivity loss encompassing both presenteeism and the actual sick-leave period. Kigozi et al. [6] emphasise the need of including both absenteeism and presenteeism in economic evaluations. In a recent study [41], the effects on productivity of absenteeism, presenteeism and problems relating to the work environment were estimated by asking managers to assess the impact of these different aspects based on assumed scenarios. It was concluded, from a societal perspective, that per-employee absenteeism was rated to have the greatest impact on productivity, followed by work-environment problems and presenteeism. It thus seems that managers may not be fully aware of the productivity loss due to presenteeism before and after a sick-leave period. The subjective experience of disability due to musculoskeletal and mental health complaints are often "unseen" and hard to verify in bio-medical assessments. In particular, mental disorders are difficult for the employee to communicate and supervisors may be reluctant to discuss the problems [38, 42]. Presenteeism and the associated productivity loss may therefore be more difficult for supervisors to observe, compared with sickness absence. A recent review article [6] concluded that presenteeism costs 
are rarely included in cost-effectiveness and cost-of-illness studies. In cost-of-illness studies related to MSD or CMD where presenteeism was included, its impact on total costs was substantial [43-45].

Inherent to the discussion and calculation of productivity loss is the societal question of balance between presenteeism and absenteeism. There is no obvious answer as to how presenteeism and absenteeism can be balanced. According to Wynne-Jones et al. [29], presenteeism and sickness absence have strong moral components: people express the need to be seen as good workers and thus presenteeism may be a social norm. At the societal level, there is an implicit "activation" philosophy in disability management regulations and policies, supported by research showing that, in general, work is good for health. Activation policies may enforce attitudes and norms at the workplace to minimise sickness absence. This leads to increased efforts to shorten or avoid sick leave and promote early return to work, which may lead to presenteeism. It is reasonable to assume that, in some cases, during the reintegration period after sick leave, employees will need time to adapt and regain their normal work ability/work pace. This is more obvious after long periods of sick leave, as long-term sick leave is negatively associated with a sustainable return to work and functionality in the labour market $[46,47]$. The employer costs due to lost productivity and costs due to adjustments at the workplace are so far rarely discussed.

Our results are dependent on the methods used to measure productivity loss in terms of presenteeism and the productivity of replacements. We used ratings by supervisors, assuming that they are more representative of the employer perspective. The relationship and trust between supervisors and employees, supervisory skills in responding to mental disorders, workplace climate and other factors may affect report bias [48] in both self-reports and supervisory ratings. More research is needed to investigate the correspondence between self-reports and supervisory ratings on work productivity [17, 29] and to develop the methods used to estimate presenteeism and economic evaluations [6].

\subsection{Study limitations and strengths}

The number of days of sick leave was restricted to the point in time when the supervisor returned the questionnaire, irrespective of whether the employee had returned to work or not. The productivity loss calculated here is therefore an underestimate of the true loss. In addition to the obvious costs that appear in employers' accounts, i.e. expenses for hiring replacements, rehabilitation measures, adjustments, and sick pay (2 weeks in Sweden), employers also incur costs due to decreased productivity that are not directly visible. This study focused only on lost productivity. 
The study comprised individuals who had been sick-listed due to MSD or CMD for at least 30 days, and the results are therefore not necessarily generalisable to all sick-listed employees. The most obvious limitation, however, is the small number of subjects in the study, making it difficult to perform further analyses. A few limitations were associated with the questionnaire. Firstly, supervisors were asked about productivity after return to work only if the employee had returned to their previous working hours. Secondly, supervisors were not given the response option to record when a replacement had performed better than the regular employee.

A strength of our study is that we have applied a real-world approach to productivity associated with sick leave. The analysis described in this paper adds to the understanding of the costs incurred by employers in relation to cases of sick leave. The results underscore the importance of disability management policies, good working conditions and good management.

\section{Conclusions}

Productivity loss due to presenteeism and sick leave amount to an average of almost 10 weeks of lost productivity per employee sick-listed due to MSD or CMD for 30 days or more. In this study, lost productivity due to presenteeism before and after sick-leave was estimated to be higher compared with lost productivity during sickness absence.

As also found in other studies, employees who were sick-listed due to CMD needed longer time to regain their normal work ability, hence generating higher productivity loss after return to work than those who were sick-listed due to MSD. Highly educated and skilled workers generated higher productivity loss during sick leave, as replacements are harder to find for these employees. In these occupations, replacements need more time to develop the required skills for the work tasks.

Our results confirm the high costs to employers of productivity loss associated with employees' presenteeism and sick leave. Knowledge about the productivity loss due to ill health among employees may be an incentive for employers to implement work disability management policies and to establish support for supervisors to handle ill health at the workplace, both before and after sick leave. 


\section{Compliance with ethical standards}

Funding: This study was funded by [Edited for Review Process].

Conflict of interest: The authors declare that they have no conflict of interest.

Informed consent: Informed consent was obtained from all individual participants included in the study.

All procedures followed were in accordance with the ethical standards of the responsible committee on human experimentation (institutional and national) and with the Helsinki Declaration of 1975, as revised in 2000 (5). Informed consent was obtained from all patients for inclusion in the study.

This article does not contain any studies with animals performed by any of the authors.

Data availability: The datasets generated during and/or analysed during the current study are available from the corresponding author on reasonable request.

\section{References}

1.Aronsson G, Gustafsson K. Sickness presenteeism: prevalence, attendance-pressure factors, and an outline of a model for research. Journal of occupational and environmental medicine.

2005;47(9):958-66.

2.Bevan S. Economic impact of musculoskeletal disorders (MSDs) on work in Europe. Best practice \& research Clinical rheumatology. 2015;29(3):356-73.

3.Evans-Lacko S, Knapp M. Global patterns of workplace productivity for people with depression: absenteeism and presenteeism costs across eight diverse countries. Social psychiatry and psychiatric epidemiology. 2016;51(11):1525-37.

4.Persson J, Bernfort L, Wahlin C, Oberg B, Ekberg K. Costs of production loss and primary health care interventions for return-to-work of sick-listed workers in Sweden. Disability and rehabilitation. 2015;37(9):771-6.

5.Zhang W, Bansback N, Anis AH. Measuring and valuing productivity loss due to poor health: A critical review. Soc Sci Med. 2011;72(2):185-92.

6.Kigozi J, Jowett S, Lewis M, Barton P, Coast J. The Estimation and Inclusion of Presenteeism Costs in Applied Economic Evaluation: A Systematic Review. Value in health : the journal of the International Society for Pharmacoeconomics and Outcomes Research. 2017;20(3):496-506.

7.Steel J, Godderis L, Luyten J. Productivity estimation in economic evaluations of occupational health and safety interventions: a systematic review. Scandinavian journal of work, environment \& health. 2018.

8.Brouwer WBF, Koopmanschap MA, Rutten FFH. Productivity costs measurement through quality of life? A response to the recommendation of the Washington Panel. Health economics. 1997;6(3):2539.

9.van den Heuvel SG, Geuskens GA, Hooftman WE, Koppes LLJ, van den Bossche SNJ. Productivity loss at work; health-related and work-related factors. J Occup Rehabil. 2010;20:331-9.

10.Arnold D. Determinants of the Annual Duration of Sickness Presenteeism: Empirical Evidence from European Data. Labour-Engl. 2016;30(2):198-212. 
11.Aronsson G, Gustafsson K, Dallner M. Sick but yet at work. An empirical study of sickness presenteeism. Journal of epidemiology and community health. 2000;54(7):502-9.

12.Bergstrom G, Bodin L, Hagberg J, Lindh T, Aronsson G, Josephson M. Does sickness presenteeism have an impact on future general health? International archives of occupational and environmental health. 2009;82(10):1179-90.

13.Brouwer WBF, van Exel NJA, Koopmanschap MA, Rutten FFH. Productivity costs before and after absence from work: as important as common? Health Policy. 2002;61:173-87.

14.Stewart WFS, Ricci JA, Chee E, Hahn SR, Morganstein D. Cost of lost productive work time among US workers with depression. Eur J Public Health. 2005;15:26-.

15.Bergstrom G, Bodin L, Hagberg J, Aronsson G, Josephson M. Sickness presenteeism today, sickness absenteeism tomorrow? A prospective study on sickness presenteeism and future sickness absenteeism. Journal of occupational and environmental medicine. 2009;51(6):629-38.

16.Tompa E, Dolinschi R, de Oliveira C, Irvin E. A systematic review of occupational health and safety interventions with economic analyses. Journal of occupational and environmental medicine.

2009;51(9):1004-23.

17.Uegaki K, de Bruijne MC, van der Beek AJ, van Mechelen W, van Tulder MW. Economic Evaluations of Occupational Health Interventions from a Company's Perspective: A Systematic Review of Methods to Estimate the Cost of Health-Related Productivity Loss. J Occup Rehabil 2011;21(1):90-9.

18.Soklaridis S, Cassidy JD, van der Velde G, Tompa E, Hogg-Johnson S. The economic cost of return to work: an employer's perspective. Work. 2012;43(3):255-62.

19.Vanni K, Virtanen P, Luukkaala T, Nygard CH. Relationship between perceived work ability and productivity loss. International journal of occupational safety and ergonomics : JOSE.

2012;18(3):299-309.

20.Lerner D, Amick BC, 3rd, Rogers WH, Malspeis S, Bungay K, Cynn D. The Work Limitations Questionnaire. Medical care. 2001;39(1):72-85.

21.Reilly MC, Zbrozek AS, Dukes EM. The validity and reproducibility of a work productivity and activity impairment instrument. PharmacoEconomics. 1993;4(5):353-65.

22.Kessler RC, Barber C, Beck A, et al. The World Health Organization Health and Work Performance Questionnaire (HPQ). Journal of occupational and environmental medicine. 2003;45(2):156-74.

23.Koopman C, Pelletier KR, Murray JF, et al. Stanford presenteeism scale: health status and employee productivity. Journal of occupational and environmental medicine. 2002;44(1):14-20.

24.Koopmanschap MA. PRODISQ: a modular questionnaire on productivity and disease for economic evaluation studies. Expert review of pharmacoeconomics \& outcomes research. 2005;5(1):23-8. 25. Kigozi J, Jowett $S$, Lewis $M$, Barton $P$, Coast J. Estimating productivity costs using the friction cost approach in practice: a systematic review. The European journal of health economics : HEPAC : health economics in prevention and care. 2016;17(1):31-44.

26. Heidemeier $\mathrm{H}$, Moser K. Self-other agreement in job performance ratings: a meta-analytic test of a process model. The Journal of applied psychology. 2009;94(2):353-70.

27.Munir F, Randall R, Yarker J, Nielsen K. The influence of employer support on employee management of chronic health conditions at work. J Occup Rehabil. 2009;19(4):333-44.

28.Tjulin A, Maceachen E, Ekberg K. Exploring the meaning of early contact in return-to-work from workplace actors' perspective. Disability and rehabilitation. 2011;33(2):137-45.

29.Wynne-Jones G, Buck R, Porteous C, et al. What Happens to Work if you're Unwell? Beliefs and Attitudes of Managers and Employees With Musculoskeletal Pain in a Public Sector Setting. J Occup Rehabil 2011;21(1):31-42.

30.Wu H, Sears LE, Coberley CR, Pope JE. Overall Well-Being and Supervisor Ratings of Employee Performance, Accountability, Customer Service, Innovation, Prosocial Behavior, and Self-

Development. Journal of occupational and environmental medicine. 2016;58(1):35-40. 
31.Prasad $M$, Wahlqvist $P$, Shikiar $R$, Shih $Y C$. A review of self-report instruments measuring healthrelated work productivity: a patient-reported outcomes perspective. PharmacoEconomics.

2004;22(4):225-44.

32.Braakman-Jansen LM, Taal E, Kuper IH, van de Laar MA. Productivity loss due to absenteeism and presenteeism by different instruments in patients with RA and subjects without RA. Rheumatology (Oxford). 2012;51(2):354-61.

33.Noben CY, Evers SM, Nijhuis FJ, de Rijk AE. Quality appraisal of generic self-reported instruments measuring health-related productivity changes: a systematic review. BMC public health.

2014;14:115.

34.Ospina MB, Dennett L, Waye A, Jacobs P, Thompson AH. A Systematic Review of Measurement Properties of Instruments Assessing Presenteeism. The American journal of managed care.

2015;21(2):E171-E85.

35.OECD. Sick on the Job? Myths and realities about mental health and work: OECD; 2012 January 17, 2012.

36.Lidwall U, Bill S, Palmer E, Bohlin CO. Mental disorder sick leave in Sweden: A population study. Work-a Journal of Prevention Assessment \& Rehabilitation. 2018;59(2):259-72.

37.Jakobsen K, Svendsen E. Employers' perspective: When a return to work is the objective for persons with reduced mobility. Work-a Journal of Prevention Assessment \& Rehabilitation. 2013;44(2):145-53.

38.Jansson I, Gunnarsson AB. Employers' views of the impact of mental health problems on the ability to work. Work-a Journal of Prevention Assessment \& Rehabilitation. 2018;59(4):585-98. 39.Pilipiec $P$. The role of time in the relation between perceived job insecurity and perceived job performance. Work. 2020;66:3-15.

40.Merrill RM, Aldana SG, Pope JE, Anderson DR, Coberley CR, Whitmer RW. Presenteeism according to healthy behaviors, physical health, and work environment. Population health management.

2012;15(5):293-301.

41.Stromberg C, Aboagye E, Hagberg J, Bergstrom G, Lohela-Karlsson M. Estimating the Effect and Economic Impact of Absenteeism, Presenteeism, and Work Environment-Related Problems on Reductions in Productivity from a Managerial Perspective. Value in health : the journal of the International Society for Pharmacoeconomics and Outcomes Research. 2017;20(8):1058-64.

42.Lemieux P, Durand MJ, Hong QN. Supervisors' Perception of the Factors Influencing the Return to Work of Workers with Common Mental Disorders. Journal of Occupational Rehabilitation.

2011;21(3):293-303.

43.Boonen A, Brinkhuizen T, Landewe R, van der Heijde D, Severens JL. Impact of ankylosing spondylitis on sick leave, presenteeism and unpaid productivity, and estimation of the societal cost. Annals of the rheumatic diseases. 2010;69(6):1123-8.

44.Cooksey R, Husain MJ, Brophy S, et al. The Cost of Ankylosing Spondylitis in the UK Using Linked Routine and Patient-Reported Survey Data. PloS one. 2015;10(7):e0126105.

45.Li X, Gignac MA, Anis AH. The indirect costs of arthritis resulting from unemployment, reduced performance, and occupational changes while at work. Medical care. 2006;44(4):304-10.

46.Vingard E, Alexanderson K, Norlund A. Chapter 9. Consequences of being on sick leave. Scand J Public Healt. 2004;32:207-15.

47. Hultin H, Lindholm C, Moller J. Is There an Association between Long-Term Sick Leave and Disability Pension and Unemployment beyond the Effect of Health Status? - A Cohort Study. PloS one. 2012;7(4).

48.Nelson CC, Shaw W, Robertson M. Supervisors and presenteeism: How do supervisors accommodate and support skilled workers with chronic health concerns? Employ Respons Rights J. 2016;28(4). 
